destruction $^{2}$ and the paravertebral abscess, and in this respect is more sensitive than plain radiography. Aspiration of the abscess collection may also be performed under CT guidance to confirm the diagnosis, as was the case in this patient. Magnetic resonance imaging can also accurately define the extent of both bone and soft tissue disease. ${ }^{3}$

The major differential diagnosis is malignancy, both primary and secondary. This is not usually associated with loss of disc space height, although it may rarely occur with lymphoma and myeloma. Loss of the vertebral end plates tends to occur earlier in pyogenic

1 Chapman M, Murray RO, Stoker DJ. Tuberculosis of the bones and joints. Semin Roentgenol 1979; 14: 266-82.

2 Jain R, Sawhney S, Berry M. Computed tomography of veterbral tuberculosis: patterns of bone destruction. Clin Radiol 1993; 47: 196-9. osteomyelitis than in tuberculosis, but vertebral body subluxation may be seen in both conditions. In caucasian patients a marked periosteal reaction favours pyogenic infection. Other infections that may rarely cause a similar picture are fungi, actinomycosis, hydatid disease, and histoplasmosis.

\section{Final diagnosis}

Tuberculous spondylitis with paravertebral cold abscess.

Keywords: tuberculous spondylitis

3 Liu GC, Chou MS, Tsai TC, Lin SY, Shen YS. Magnetic resonance evaluation of tuberculous spondylitis. Acta Radio 1993; 34: 554-8.

\title{
An unusual but important cause of sciatica
}

\author{
SKC Toh, S Ellis, V Bahal
}

An 85-year-old man presented to the rheumatologist with a three-year history of increasingly severe lower backpain, radiating down both his legs, with reduced straight-leg raising and a positive sciatic-nerve stretch test. He had no urinary or bowel symptoms, and abdominal examination was unremarkable. As part of his management, he had an epidural with a local anaesthetic, resulting in acute urinary retention. Rectal examination performed after catheterisation revealed a 'pulsatile' prostate. Ultrasound scan (figure 1) and computed tomography (CT) (figure 2) of the pelvis were then obtained.

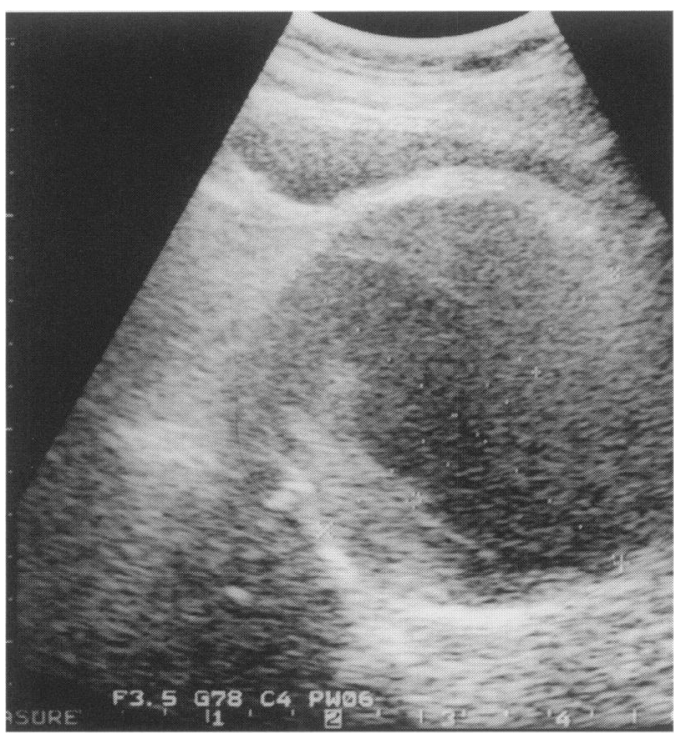

Figure 1 Ultrasound scan of the pelvis

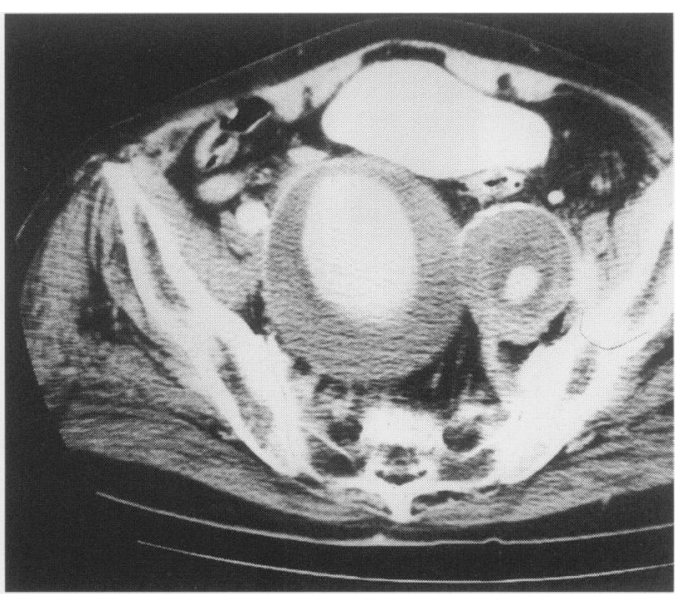

Figure 2 CT scan of the pelvis

East Surrey Hospital, Redhill, Surrey RH1 5RH, UK

SKC Toh

S Ellis

V Bahal

Correspondence to

SKC Toh, University

Surgical Unit, Southampton

General Hospital, Tremona

Road, Southampton

SO16 6YD, UK

\section{Questions}

1 What is the diagnosis?

2 How may this condition present?

3 What further investigations and management may be advised? 
Answers

\section{QUESTION 1}

Multiple iliac aneurysms. Careful abdominal, rectal and vaginal examination may lead to the diagnosis in $70 \%$ of cases. ${ }^{1}$ The ultrasound scan demonstrated one of these aneurysms. CT scan showed bilateral internal iliac aneurysms $(9 \times 8 \mathrm{~cm}$ right and $5 \times 6 \mathrm{~cm} \mathrm{left})$.

\section{QUESTION 2}

Iliac aneurysms represent less than $2 \%$ of intraabdominal aneurysms, although the incidence is increasing with the advanced longevity of the population and with improved detection. They are often associated with aortic aneurysms, and are rarely isolated. Even when confined to the iliac vessels, $70 \%$ are multiple rather than solitary aneurysms.

Up to $45 \%$ may be asymptomatic until they rupture. In these patients, clinical suspicion should be roused in any patient with risk factors for atherosclerotic disease or the presence of aneurysmal disease elsewhere (this patient, in fact, had a known anterior communicating artery aneurysm). In patients having ultrasound screening for aortic aneurysms, attempts have been made to examine the iliac vessels, although because of bowel gas, obesity and vessel tortuosity, this can sometimes be difficult.

Due to the limited number of cases and

Figure 3 Digital subtraction arteriography of the iliac vessels

Figure 4 Operative findings
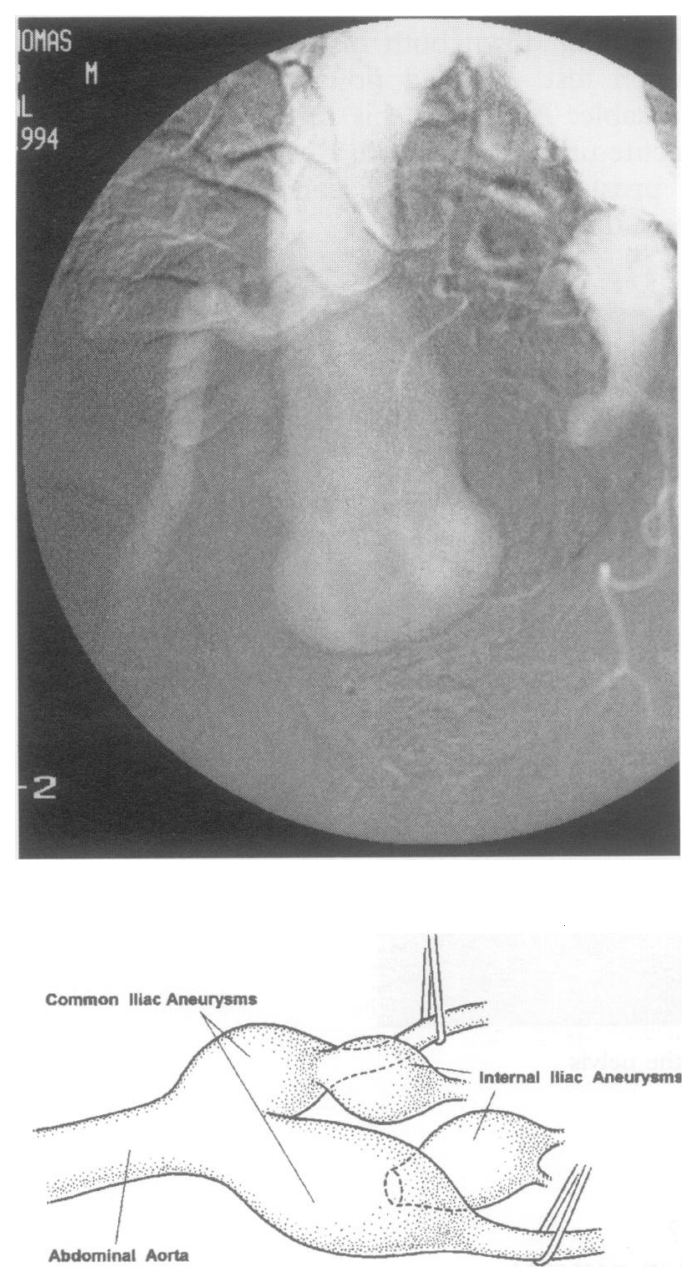

series reported, no correlation of size and site with risk of rupture has been made, although the risk of rupture appears high and apparently unrelated to aneurysm size. Nevertheless, the evidence so far has led some authors to recommend repair of any iliac aneurysm greater than $3 \mathrm{~cm}$ in diameter. ${ }^{2,3}$ All these patients should be considered for surgery as elective surgery carries a significantly better operative mortality $(7-11 \%)$ than emergency repair of rupture $(20-57 \%)$.

About $70 \%$ of patients present acutely with a leaking or ruptured aneurysm. Some patients may present with compression and erosion of surrounding structures including the bowel, bladder, ureters, pelvic veins and nerve roots resulting in vascular-enteric fistulae, haematuria, renal colic, arteriovenous fistulae and sciatic pain, respectively. In particular, nerve root compression may be chronic or acute, the latter suggesting impending or actual leak requiring urgent surgery.

This patient illustrates well the elusive nature of this condition. Careful rectal examination was the key to diagnosis.

\section{QUESTION 3}

The patient was increasingly debilitated by his symptoms and was keen to have further treatment. As he was slender and remarkably fit for his age, he was referred for surgical assessment. It is important to emphasise that surgery in this age group is not without increased risks but the patient was aware of this and remained adamant that he wished to proceed. If the patient had had little or no symptoms, it may have been justifiable to perform serial ultrasound scans of his iliac vessels and contemplate surgery only if there were increase in size of the aneurysms. Digital subtraction arteriography was performed to defined the aneurysms which appeared to be confined to the iliac vessels (figure 3 ). At operation, he was found to have aneurysmal common and internal iliac vessels (figure 4). The common iliac aneurysms were ligated and replaced with a bifurcation Dacron aorto-iliac graft. There was found to be good backflow distal to the internal iliac aneurysms which were safely ligated, the anterior walls excised and obliterative endoaneurysmorrhaphy performed. The surgical points to note are that distal control is vital to achieve safe control of internal iliac aneurysms ${ }^{4}$ and that the presence of good backflow meant that isolation of both internal iliac arteries can be safely done without risk of colonic or perineal ischaemia. ${ }^{5}$

The patient made a good recovery with relief of his symptoms and remained well one year on.

\section{Final diagnosis}

Multiple iliac aneurysms.

Keywords: iliac aneurysm, sciatica

We wish to thank Peter Jack, Medical Artist, University of Southampton for figure 4 . 
1 Richardson JW, Greenfield LJ. Natural history and management of iliac aneurysms. $f$ Vasc Surg 1988; 8: $165-71$.

2 McCready RA, Pairolero P, Gilmore J, Kazmier F, Cherry K, Hollier L. Isolated iliac artery aneurysms. Surgery 1983 93: $688-93$.

3 Thiele B, Geddes N, Johnson N, MacLeish D, Royle J, Buxton B. Ruptured iliac aneurysms. Aust NZ F Surg 1975; 45: $417-21$.
4 Sacks NPM, Huddy SPJ, Wegner T, Giddings AEB Management of solitary iliac aneurysms. $f$ Cardiovasc Sur 1992; 33: $679-83$.

5 Byrne JL, Zaman SN, Meade JW, Aronski WP. Operative management of bilateral internal iliac artery aneurysms. $f$ Cardiovasc Surg 1989; 30: 241-3.

\title{
Breathlessness in an Afro-Caribbean woman
}

\author{
HRS Roberts, DM Hansell, R Wilson, PJ Cole, CRK Hind
}

A 32-year-old Afro-Carribbean woman presented with a two-month history of weight loss and pleuritic chest pain, and a two-week history of night sweats, and cough productive of bloodstained green sputum. She had no previous respiratory history of note, was not aware of having had tuberculosis, had no haemoglobinopathy, and denied exposure to risk factors for HIV infection. Examination was unremarkable apart from signs of left upper lobe consolidation, which was confirmed by chest radiography. Sputum microscopy revealed acid-alcohol fast bacilli. Antituberculous therapy (rifampacin, isoniazid, and ethambutol with pyridoxine) was started.

Despite the treatment she became increasingly breathless over the next few days, until she was dyspnoeic at rest. She refused an HIV test. Examination one week after the start of therapy revealed: no pyrexia, a pulse of 100 beats/minute and regular, blood pressure $120 / 80 \mathrm{mmHg}$ (no postural drop), no murmurs, a respiratory rate of 28 per minute, and features of left upper lobe consolidation/collapse. Investigations showed: haemoglobin $9.6 \mathrm{~g} / \mathrm{dl}$, white cell count $14.1 \times 10^{9}$ / 1, platelets $374 \times 10^{9} / 1$, normal serum urea and electrolytes; arterial blood gases: $\mathrm{pH} 7.43$ (7.42), $\mathrm{PaCO} 23.99 \mathrm{kPa}$ (3.78), $\mathrm{PaO} 2 \mathrm{kPa} 5.95$ (9.80), bicarbonate $23 \mathrm{mmol} / \mathrm{l}$ (22), oxygen saturation $85 \%(96 \%)$ while breathing room air (figures in brackets while breathing $60 \%$ oxygen); electrocardiogram was normal; the collapse/consolidation of the left upper lobe was unchanged on chest X-ray. Prednisolone $60 \mathrm{mg}$ daily was added to the treatment.

Over the next 48 hours her breathlessness continued to increase, and her tachycardia increased to 130 beats/minute, but the findings on examination were otherwise unchanged. An arterial sample acquired while the inspired oxygen fraction was $60 \%$ showed: $\mathrm{pH} 7.52, \mathrm{PaCO} 24.02 \mathrm{kPa}$, $\mathrm{PaO} 27.13 \mathrm{kPa}$, bicarbonate $24 \mathrm{mmol} / 1$. A chest $\mathrm{X}$-ray was performed (figure 1 ).

Royal Brompton Hospital, London SW3 6NP, UK

HRS Roberts

DM Hansell

R Wilson

PJ Cole

\section{Royal Liverpool}

University Hospital, Liverpool L7 8XP, UK CRK Hind

Correspondence to Dr DM Hansell

Accepted 14 August 1995

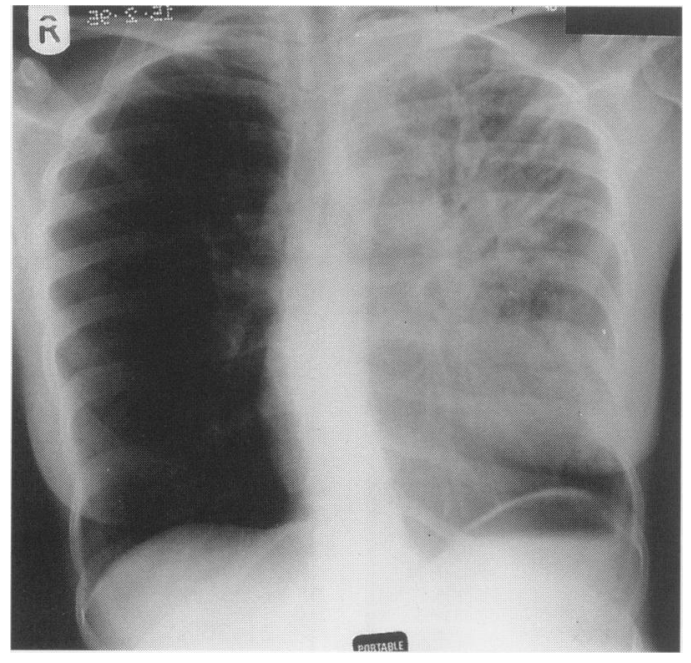

\section{Questions}

1 What is the likely explanation for the patient's increasing breathlessness?

2 Which imaging techniques might you use to reach the correct diagnosis?

Figure 1 Chest X-ray at initial examination 